\title{
COMMENT
}

\section{Early Career Investigator Highlight Biocommentary}

Robert Galinsky ${ }^{1,2}$

Pediatric Research (2020) 88:7; https://doi.org/10.1038/s41390-020-0909-3

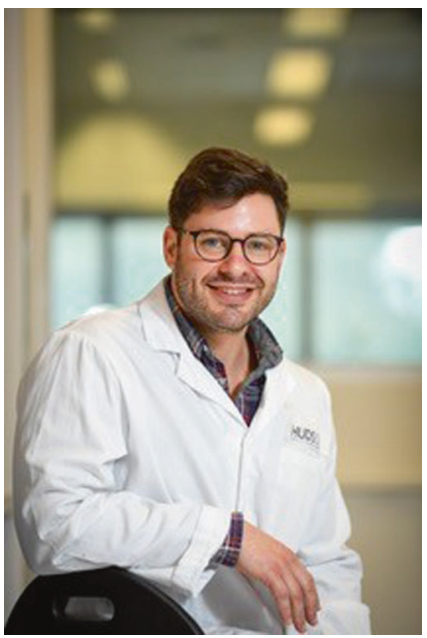

I obtained my Ph.D. in 2013 in the Department of Obstetrics and Gynaecology at Monash University, Australia. My thesis focused on how inflammation during pregnancy affects the baby's cardiovascular system before and after birth. My passion for perinatal physiology stemmed from my biomedical studies at Monash University. I was captivated by the alternate universe that is the intrauterine environment, as well as the dynamic and complex nature of the physiological changes that occur inside the fetus as it transitions into a newborn. I distinctly recall one of my lecturers, Professor Stuart Hooper who is now a mentor, describing this transitional period as one of the most physiologically stressful experiences in our lifetime.

After completing my Ph.D., I moved to New Zealand where I was mentored by Professors Alistair Gunn and Laura Bennet at the Department of Physiology, University of Auckland. Training with Alistair and Laura added a new dimension to my understanding of perinatal physiology and neuroscience. As exceptional advisors, Professors Gunn and Bennet supported me in obtaining competitive project and fellowship grant funding. This approach involved securing seed-funding that enabled me to generate preliminary data for a successful trainee fellowship and a project grant from the National Health and Medical Research Council (NHMRC), Australia's peak health and medical research body, for which the funding rate is only $10-13 \%$.

After recently returning to Australia on an NHMRC CJ Martin Fellowship, I have developed my own research program in perinatal neuroscience and physiology, which continues to evolve with the support of my mentors in Australia and New Zealand.

Our team focuses on how brain inflammation during pregnancy or shortly after birth leads to impaired cell development and function, and how anti-inflammatory interventions could help restore healthy brain development to reduce the incidence and severity of disability. We use an integrated approach that spans the disciplines of developmental neuroscience and physiology, medical imaging, bioengineering and translational science. This collaborative program includes teams of experts across Australia, New Zealand, Europe, the UK and US.

My advice to those coming along behind me is to surround yourself with remarkable people that bring out the best version of you. I'm very fortunate to have outstanding mentors and an incredibly supportive family. I also can't stress enough how important is to find solace away from work, which for me includes any kind of exercise and hanging out with my wife and kids.

\section{ACKNOWLEDGEMENTS}

R.G. is supported by the CJ Martin Fellowship and a project grant from the National Health and Medical Research Council of Australia (1090890 and 1164954), the Cerebral Palsy Alliance and the Victorian Government's Operational Infrastructure Support Program.

\section{ADDITIONAL INFORMATION}

Competing interests: The author declares no competing interests.

Publisher's note Springer Nature remains neutral with regard to jurisdictional claims in published maps and institutional affiliations.

\footnotetext{
${ }^{1}$ The Ritchie Centre, Hudson Institute of Medical Research, Melbourne, VIC, Australia and ${ }^{2}$ Department of Obstetrics and Gynaecology, Monash University, Melbourne, VIC, Australia

Correspondence: Robert Galinsky (Robert.Galinsky@hudson.org.au)
}

Received: 30 March 2020 Accepted: 2 April 2020

Published online: 19 April 2020 